\title{
LOCAL ANAESTHETIC TOXICITY DUE TO THE MIGRATION OF AN EPIDURAL CATHETER: A RARE COMPLICATION DUE TO A RARE SITUATION
}

Rodríguez Prieto M, Hinojal Blanco I, García Álvarez M, González Carrasco FJ, Moral MV Dept of Anaesthesiology. Hospital de Sant Pau, Barcelona, Spain

\section{BACKGROUND}

Local anaesthetics (LA) can cross cell membranes and interact with charged targets and signaling systems. For that reason, they produce a variety of toxic effects in several tissue types: heart, brain and skeletal muscle. LA systemic toxicity (LAST) occurs in 1:10,000 for epidurals, but this data is not clear due to the low incidence. Infusion of $20 \%$ lipid emulsion to treat severe systemic drug toxicity is the election treatment in this situation.

CASE REPORT 24 year old parturient woman, with no diseases and no allergies.

\section{Epidural analgesia:}

- No difficulties. Epidural space: $5 \mathrm{~cm}$ - catheter placed at $10 \mathrm{~cm}$. Aspiration test $\odot$.

- Test dose: $0.25 \%$ bupivacaine with epinephrine $5 \mathrm{mcg} / \mathrm{ml}(3 \mathrm{ml}):-$.

- $0.0625 \%$ bupivacaine infusion at $12 \mathrm{ml} / \mathrm{h}$.

During labor:

- After 4 hours with no incidences and optimal analgesia, the anaesthesiologist was called due to patient's pain.

- Before using the placed catheter, syringe aspiration obtained blood. After reviewing the catheter's position, it was noticed that it was placed at $13 \mathrm{~cm}, 3$ more inside than before.

- While these manoeuvres were being performed, the patient presented metallic taste, dizziness, visual and auditory disturbances, disorientation and drowsiness.

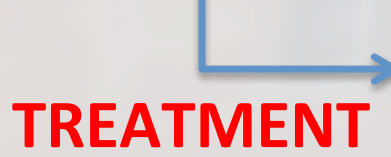

STOP LA infusion, lipid emulsion $20 \%$, monitoring, get help, drugs in case cardiac arrest

- After 5 minutes, the patient recovered ad integrum. Toxic doses of local anaesthetic were not reached.

\section{DISCUSSION}
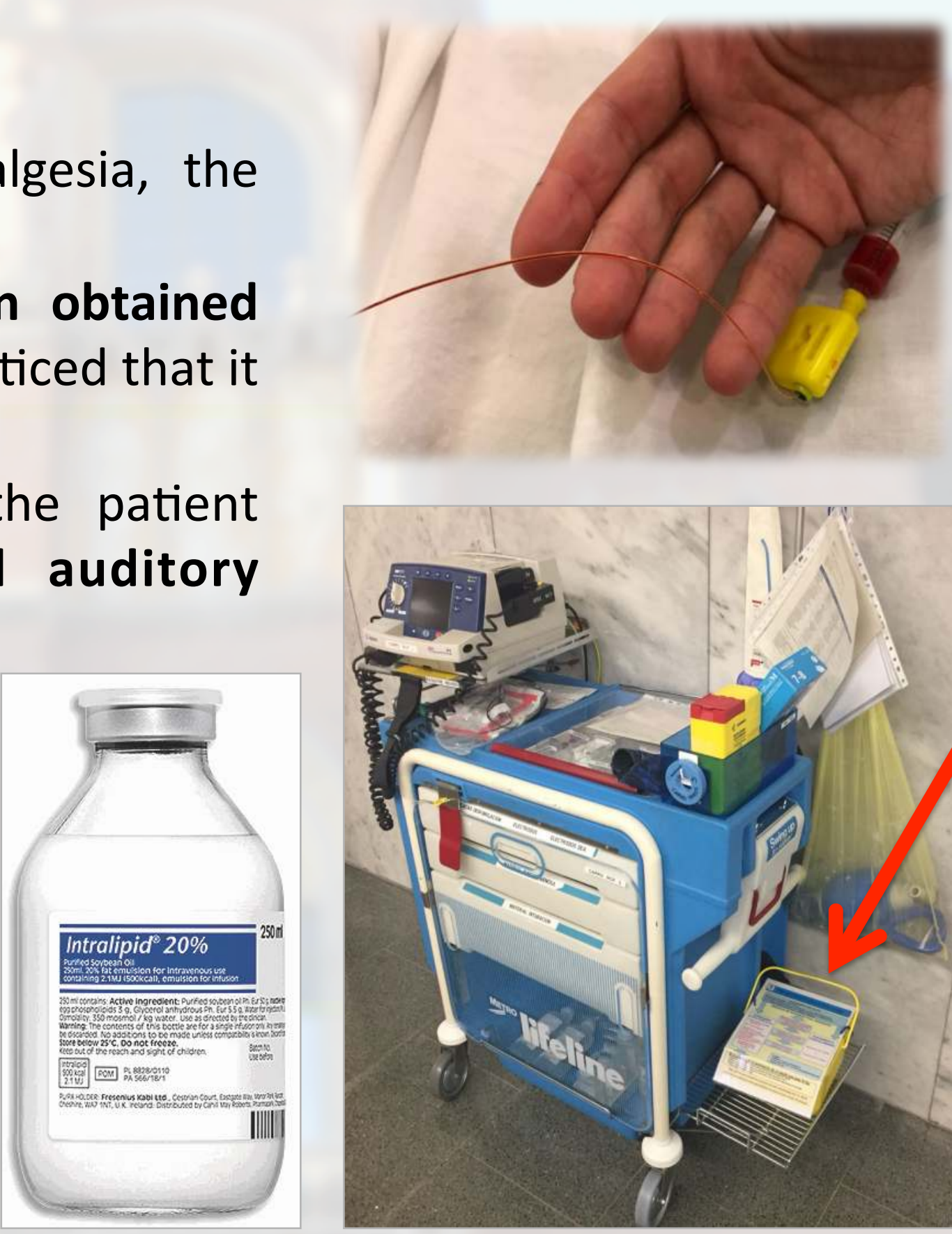

Even though the catheter was initially correctly placed, it seems that vascular migration is the cause of the toxicity, even though we have not found any described case in the literature. Lipid Rescue seems to be an effective treatment, according to our experience and the several case reports found after our review. More data is needed: the current knowledge is only about reports of cases, due to the low incidence of this entity.

\section{LEARNING POINTS}

$\checkmark$ LAST is a rare condition that can be devastating.

$\checkmark$ Due to the low incidence, reporting the cases is essential to learn about how to treat it.

$\checkmark$ Intravascular infusion of LA, especially bupivacaine, is a potentially dangerous cause of toxicity.

$\checkmark$ Once the diagnosis is suspected, lipid rescue must be started. This includes asking for help. 